Article

\title{
Study on the Influence of Clogging on the Cooling Performance of Permeable Pavement
}

\author{
Jianguang Xie * iD, Sicheng Jia, Hua Li and Lei Gao \\ Department of Civil Engineering, Nanjing University of Aeronautics and Astronautics, Nanjing 210016, China; \\ jiasc1993@163.com (S.J.); lihua112358@gmail.com (H.L.); glzjy@nuaa.edu.cn (L.G) \\ * Correspondence: xiejg@nuaa.edu.cn
}

Received: 6 February 2018; Accepted: 5 March 2018; Published: 10 March 2018

\begin{abstract}
Permeable pavement is often known as "cool road". However, the cooling performance will be weakened due to clogging. In this paper, the temperature field distribution model of asphalt pavement was obtained by Green's function. Gradations of porous asphalt mixture were designed to obtain different porosities, and the thermal properties of specimens with different porosities were tested and calculated. The simulation test was carried out to obtain the heating curves, which were used to verify the accuracy of the temperature model by comparing the results of the theoretical calculation to results of the test. The daily solar radiation intensity and air temperature changing functions were plugged into the model to calculate the temperature at the bottom of the middle surface. In this way, the simplified model of void fraction and cooling performance of the porous asphalt pavement was obtained. The results showed that the temperature at the bottom of the middle surface for permeable pavement was lower than that for traditional asphalt pavements. The gap was between 0.29 to $2.75{ }^{\circ} \mathrm{C}$ and it increased as the porosity of permeable pavement increased.
\end{abstract}

Keywords: sponge city; permeable pavement; Green's function; cooling performance

\section{Introduction}

As an important part of a "sponge city", permeable pavement plays a significant role in regulating local climate, accelerating groundwater recycling and reducing runoff on road surface. Permeable pavement is also known as "cool road". Due to its porous structure, the maximum temperature in the permeable pavement is lower than that in traditional asphalt pavement in summer [1]. The maximum temperature of asphalt pavement affects the service and safety performance. Problems such as rutting and deflection are more likely to occur as the maximum temperature rises, leading to instability failures [2-5]. The difference between the maximum temperatures of the permeable asphalt pavement and traditional asphalt pavement is defined as the cooling performance of permeable asphalt pavement. In the long-term use of permeable pavement, the study found that it was easily affected by the environment and the compaction conditions, leading to void clogging [6-8], weakening its permeability characteristics, and also affecting the cooling performance.

The numerical analysis method is often used to predict the temperature distribution internal to the pavement [9-12]. This method is based on finite element or finite difference method. In these numerical models, pavement structures are discretized into elements for solving governing equations. However, the accuracy of the calculation results is highly dependent on the density of the mesh and total number of elements in the model.

Different from the numerical analysis method, the analytical method can be used to obtain the rigorous solutions of pavement temperature fields with appropriate assumptions. Additionally, various transfer methods were used in the analytical method. With this approach, each layer of the pavement was treated as isotropic [13]. Based on the Fourier-Biot heat conduction 
equation and transform methods such as Laplace transform method and Green Function method, an analytical solution to heat conduction can be obtained very fast by solving the initial boundary value problems. The solution is usually an equation of instant temperature, thermal properties of materials in each layer and the heat flux on the surface of pavement [14-16]. Comparing with the numerical analysis method, the analytical method is more convenient and accurate. So the analytical method was adopted in the paper.

According to the analytical method, the changing rule between thermal properties and porosity of the asphalt mixture should be studied first. Then the maximum internal temperatures of the pavement can be obtained, based on which the changing rule of cooling performance with void clogging can also be obtained.

\section{Objective}

This paper aims to establish a prediction model of the cooling performance decline for layered permeable pavements due to clogging problems. In order to achieve the objective, both theoretical analysis and laboratory test were performed. The Green's function method was used in the prediction of pavement temperature fields. The thermal properties of porous asphalt mixture with different porosities were tested in laboratory. Finally, the cooling performance was represented by the difference between the maximum temperatures in the permeable asphalt pavement and traditional pavement.

\section{Pavement Temperature Field with Green's Function Method}

\subsection{Heat Conduction Model of Multilayer Pavement Structure}

Because the horizontal dimension of each layer of the pavement is much larger than the vertical direction, the heat conduction problem of the pavement can be regarded as the heat conduction problem of the large flat plate. Therefore, in the prediction of the temperature field, the method of one-dimensional heat conduction was adopted [17-19]. The pavement structure is shown in Figure 1. At the surface of the pavement $z=z_{0}=0$. The surface is considered as a mixed boundary where the pavement receives the solar radiation, radiates part of the heat into the atmosphere and exchanges heat with the air. When the depth is infinitely deep, the temperature can be considered as a constant.

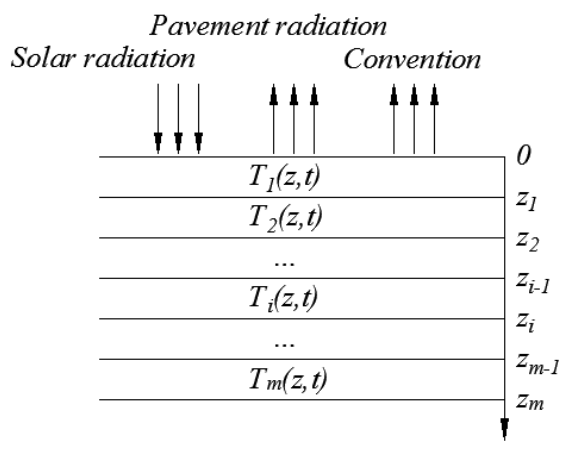

Figure 1. Heat transfer diagram of multilayered pavement system.

According to the theory of heat transfer, heat conduction and heat convection that occurred due to direct contact between fluid and solid are called convention heat transfer, which can be calculated according to Newton cooling formula:

$$
q_{r}=h_{r}\left(T_{\text {surf }}-T_{\text {air }}\right)
$$

where $q_{r}$ is the heat flux when convective heat transfer occurs, $\mathrm{W} \cdot \mathrm{m}^{-2} \cdot \mathrm{s}^{-1} ; h_{r}$ is convective heat transfer coefficient, $\mathrm{W} /\left(\mathrm{m}^{2} \cdot \mathrm{K}\right) \cdot T_{\text {surf }}$ is the temperature of the surface, $\mathrm{K} ;$ and $T_{\text {air }}$ is the temperature of the air, $\mathrm{K}$. 
The energy entering the road consists of short wave radiation and long wave radiation. Meanwhile, the road will radiate outward in a long wave way. The total amount of long wave radiation energy can be expressed as the following formula:

$$
E_{L}=\varepsilon_{\mathrm{a}} \sigma_{s b} T_{\text {air }}^{4}
$$

where $E_{L}$ is the amount of long wave radiation energy, $\mathrm{W} \cdot \mathrm{m}^{-2} \cdot \mathrm{s}^{-1} ; \sigma_{s b}$ is Stefan-Boltzmann constant, $5.67 \times 10^{-8} \mathrm{~W} \cdot \mathrm{m}^{-2} \cdot \mathrm{K}^{-4}$; and $\varepsilon_{a}$ is atmospheric long wave emissivity.

The long wave radiation [9] of asphalt pavement emission can be calculated according to the following formula:

$$
q_{L}=\varepsilon \sigma_{s b} T_{\text {surf }}^{4}
$$

where $q_{L}$ is the outward amount of pavement radiation, $\mathrm{W} \cdot \mathrm{m}^{-2} \cdot \mathrm{s}^{-1}$; and $\varepsilon$ is pavement emissivity.

So the heat flux into the pavement system can be expressed as:

$$
q=\varepsilon_{e} E_{g}+\varepsilon_{f} E_{L}-q_{L}-q_{r}
$$

where $q$ is the heat flux into the pavement; $E_{g}$ is the total solar shortwave radiation, $\mathrm{W} \cdot \mathrm{m}^{-2} \cdot \mathrm{s}^{-1} ; \varepsilon_{e}$ is the absorptivity of solar shortwave radiation; and $\varepsilon_{f}$ is the absorptivity of atmospheric long wave radiation.

\subsection{Model of Temperature Field in Asphalt Pavement Based on Green's Function}

Green's function method is widely used to solve heat conduction problems, especially when the boundary conditions are nonhomogeneous. It can be used to solve single dielectric problems, as well as inhomogeneous problems for composite dielectrics. The heat conduction problem can be expressed as follows:

$$
\alpha_{i} \frac{\partial^{2} T_{i}(z, t)}{\partial z^{2}}=\frac{\partial T_{i}(z, t)}{\partial t} \quad z_{i-1}<z<z_{i}, t>0
$$

where $T_{i}(z, t)$ is the distribution of temperature in $i$-th layer, $\mathrm{K} ; z$ is the depth, $\mathrm{m}$; and $\alpha_{i}$ is the thermal diffusivity of $i$-th layer, $\mathrm{m}^{2} \cdot \mathrm{s}^{-1}$.

The boundary conditions can be expressed as follows:

$$
\begin{gathered}
-k_{1} \frac{\partial T_{1}(0, t)}{\partial z}+h_{1} T_{1}(0, t)=h_{1} f_{1}(t) \\
\left.k_{i} \frac{\partial T_{i}(z, t)}{\partial z}\right|_{z=z_{i}}=\left.k_{i+1} \frac{\partial T_{i+1}(z, t)}{\partial z}\right|_{z=z_{i}} \\
\left.T_{i}(z, t)\right|_{z=z_{i}}=\left.T_{i+1}(z, t)\right|_{z=z_{i}} \\
\left.T_{m}(z, t)\right|_{z=z_{m}}=f_{2}(t) \\
T_{i}(z, 0)=I_{i}(z)
\end{gathered}
$$

where $k_{i}$ is the thermal conductivity of $i$-th layer, $\mathrm{W} \cdot \mathrm{m}^{-1} \cdot \mathrm{K}^{-1} ; f_{1}(t)$ is the heat flux into the pavement; $f_{2}(t)$ is the distribution of temperature as $z=z_{m}$.

Construct the solution of $T_{i}(z, t)$ as the form as follows:

$$
T_{i}(z, t)=\varphi_{i}(z) f_{1}(t)+\psi_{i}(z) f_{2}(t)+\theta_{i}(z, t)
$$

where $\phi_{i}(z)$ and $\psi_{i}(z)$ are functions of $z ; f_{1}(t)$ and $f_{2}(t)$ are functions of $t$; and $\theta_{i}(z, t)$ is function of $z$ and $t$.

$\phi_{i}(z)$ should satisfy the steady state heat conduction problem given as Equation (12):

$$
\frac{d^{2} \varphi_{i}(t)}{d z^{2}}=0 \quad z_{i-1}<z<z_{i}
$$


The boundary conditions of Equation (12) are shown as Equations (13)-(16).

$$
\begin{gathered}
\left.\varphi_{m}(z)\right|_{z=z_{m}}=0 \\
\left.\varphi_{i}(z)\right|_{z=z_{i}}=\left.\varphi_{i+1}(z)\right|_{z=z_{i}} \\
\left.k_{i} \frac{d \varphi_{i}(z)}{d z}\right|_{z=z_{i}}=\left.k_{i+1} \frac{d \varphi_{i+1}(z)}{d z}\right|_{z=z_{i}} \\
-\left.k_{1} \frac{d \varphi_{1}(z)}{d z}\right|_{z=0}+\left.h_{1} \varphi_{1}(z)\right|_{z=0}=0
\end{gathered}
$$

In addition, $\psi_{i}(z)$ should satisfy the steady state heat conduction problem given as Equation (17), subjected to the boundary conditions Equations (18)-(21).

$$
\begin{gathered}
\frac{d^{2} \psi_{i}(t)}{d z^{2}}=0 \quad z_{i-1}<z<z_{i} \\
\left.\psi_{m}(z)\right|_{z=z_{m}}=1 \\
\left.\psi_{i}(z)\right|_{z=z_{i}}=\left.\psi_{i+1}(z)\right|_{z=z_{i}} \\
\left.k_{i} \frac{d \psi_{i}(z)}{d z}\right|_{z=z_{i}}=\left.k_{i+1} \frac{d \psi_{i+1}(z)}{d z}\right|_{z=z_{i}} \\
-\left.k_{1} \frac{d \psi_{1}(z)}{d z}\right|_{z=0}+h_{1} \psi_{1}(0)=\left.h_{1} f_{1}(t)\right|_{z=0}
\end{gathered}
$$

$\theta_{i}(z, t)$ should satisfy the transient state heat conduction problem given as Equations (22) and (23), subjected to the boundary conditions Equations (24)-(28).

$$
\begin{gathered}
\alpha_{i} \frac{\partial^{2} \theta_{i}(z, t)}{\partial z^{2}}+g_{i}(z, t)=\frac{\partial T_{i}(z, t)}{\partial t} \quad z_{i-1}<z<z_{i}, t>0 \\
g_{i}(z, t)=\varphi(z) \frac{d f_{1}(t)}{d t}+\psi(z) \frac{d f_{2}(t)}{d t} \\
-\left.k_{1} \frac{\partial \theta_{1}(z, t)}{\partial z}\right|_{z=0}+\left.h_{1} \theta_{1}(z, t)\right|_{z=0}=0 \\
\left.k_{i} \frac{\partial \theta_{i}(z, t)}{\partial z}\right|_{z=z_{i}}=\left.k_{i+1} \frac{\partial \theta_{i+1}(z, t)}{\partial z}\right|_{z=z_{i}} \\
\left.\theta_{i}(z, t)\right|_{z=z_{i}}=\left.\theta_{i+1}(z, t)\right|_{z=z_{i}} \\
\left.\theta_{m}(z, t)\right|_{z=z_{m}}=0 \\
\theta_{i}(z, 0)=I_{i}(z)-f_{1}(0) \varphi_{1}(x)-f_{2}(0) \psi_{1}(x) \equiv I_{i}^{*}(x)
\end{gathered}
$$

The solution of $\phi_{i}(z)$ and $\psi_{i}(z)$ can be constructed as Equations (29) and (30):

$$
\begin{aligned}
& \varphi_{i}(z)=A_{i}+B_{i} z \\
& \psi_{i}(z)=C_{i}+D_{i} z
\end{aligned}
$$

The unknown coefficients in Equations (29) and (30) can be determined by Equations (12)-(21).

Because there is no heat source inside the pavement, the solution of $\theta_{i}(z, t)$ can be constructed as $\theta_{i}(z, t)=Z(z) \Gamma(t)$; Equations (31) and (32) can be obtained as $\theta_{i}(z, t)$ substituted into Equations (22) and (23).

$$
\begin{gathered}
\frac{d \Gamma(t)}{d t}+\beta_{n}^{2} \Gamma(t)=0 \quad t>0 \\
\frac{d^{2} Z(z)}{d z^{2}}+\frac{\beta_{n}^{2}}{\alpha_{i}} Z(z)=0 \quad z_{i-1}<z<z_{i}
\end{gathered}
$$


where $\beta_{n}$ is the eigenvalue, which can be determined by Equations (22) and (23). Equations (33) and (34) can be obtained by equations above.

$$
\begin{gathered}
\Gamma(t)=e^{-\beta_{n}^{2} t} \\
Z(z)=A_{i, n} \sin \left(\frac{\beta_{n}}{\sqrt{\alpha_{i}}} z\right)+B_{i, n} \cos \left(\frac{\beta_{n}}{\sqrt{\alpha_{i}}} z\right)
\end{gathered}
$$

So $\theta_{i}(z, t)$ can be expressed as follows:

$$
\begin{gathered}
\theta_{i}(z, t)=\sum_{n=1}^{\infty} c_{n} e^{-\beta_{n}^{2} t} Z(z) \\
c_{n}=\frac{1}{N\left(\beta_{n}\right)} \sum_{i=1}^{N} \frac{k_{i}}{\alpha_{i}} \int_{z_{i}}^{z_{i+1}} Z_{i}\left(\beta_{n}, z\right) I_{i}^{*}(z) d z \\
N\left(\beta_{n}\right)=\sum_{i=1}^{N} \frac{k_{i}}{\alpha_{i}} \int_{z_{i}}^{z_{i+1}} Z_{i}^{2}\left(\beta_{n}, z\right) d z
\end{gathered}
$$

Equation (22) can be deduced as:

$$
\begin{gathered}
\theta_{i}(z, t)=\sum_{j=1}^{N} \frac{k_{j}}{\alpha_{j}} \int_{z_{j}}^{z_{j+1}}\left[\sum_{n=1}^{\infty} \frac{1}{N\left(\beta_{n}\right)} e^{-\beta_{n}^{2} t} Z_{i}\left(\beta_{n}, z\right) Z_{i}\left(\beta_{n}, z^{\prime}\right) \cdot I_{j}^{*}\left(z^{\prime}\right) d z^{\prime}\right. \\
=\left.\sum_{j=1}^{N} \int_{z_{j}}^{z_{j+1}} G_{i j}\left(z, t \mid z^{\prime}, \tau\right)\right|_{\tau=0} I_{j}^{*}\left(z^{\prime}\right) d z^{\prime}
\end{gathered}
$$

where

$$
G_{i j}\left(z, t \mid z^{\prime}, \tau\right)=\sum_{n=1}^{\infty} \frac{1}{N\left(\beta_{n}\right)} e^{-\beta_{n}^{2}(t-\tau)} Z_{i}\left(\beta_{n}, z\right) Z_{j}\left(\beta_{n}, z^{\prime}\right)
$$

According to the heat transfer theory, once the Green's function is determined, the temperature field of the pavement can be determined directly as:

$$
\begin{aligned}
& T_{i}(z, t)=\left(A_{i}+B_{i} z\right) f_{1}(t)+\left(C_{i}+D_{i} z\right) f_{2}(t) \\
& \quad+\sum_{j=1}^{N}\left[\left.\frac{k_{i}}{\alpha_{i}} \int_{z_{j}}^{z_{j+1}} G_{i j}\left(z, t \mid z^{\prime}, \tau\right)\right|_{\tau=0} I_{j}^{*}\left(z^{\prime}\right) d z^{\prime} \quad z_{i-1}<z<z_{i}, t>0\right. \\
& \quad+\left.\int_{0}^{t} G_{i 1}\right|_{z^{\prime}=0} f_{1}(\tau)
\end{aligned}
$$

\section{Test Process}

\subsection{High Viscosity Modified Asphalt}

Different from other studies, the high viscosity additive (HVA) and styrene-butadiene-styrene (SBS) block copolymer modified asphalt were used in this test. The indexes of asphalt and HVA were measured by the methods in Chinese standards. The results of SBS modified asphalt test are shown in Table 1. The test results of HVA are shown in Table 2 and the indexes of high viscosity modified asphalt modified by high viscosity additives are shown in Table 3. 
Table 1. Properties of SBS modified asphalt.

\begin{tabular}{ccc}
\hline Test & Value & Specification Limits \\
\hline Penetration $25^{\circ} \mathrm{C}, 100 \mathrm{~g}, 5 \mathrm{~s}(0.1 \mathrm{~mm})$ & 54 & $40-60$ \\
Softening point $\left({ }^{\circ} \mathrm{C}\right)$ & 88.0 & $\geq 75$ \\
Ductility, $5{ }^{\circ} \mathrm{C}, 5 \mathrm{~cm} / \mathrm{min}(\mathrm{cm})$ & 28 & $\geq 20$ \\
Density, $25^{\circ} \mathrm{C}\left(\mathrm{g} / \mathrm{cm}^{3}\right)$ & 1.031 & \\
After aging in rolling thin film oven & & \pm 1.0 \\
Mass change $(\%)$ & +0.045 & $\geq 65$ \\
Retained penetration, $25{ }^{\circ} \mathrm{C}(\%)$ & 83 & $\geq 15$ \\
Retained ductility, $5^{\circ} \mathrm{C}(\mathrm{cm})$ & 19 & \\
\hline
\end{tabular}

Table 2. Properties of high viscosity additive.

\begin{tabular}{ccc}
\hline Index & Value & Specification Limits \\
\hline Mass of single particle $(\mathrm{g})$ & 0.022 & $\leq 0.03$ \\
Density $\left(\mathrm{g} / \mathrm{cm}^{3}\right)$ & 0.978 & $0.90-1.00$ \\
Appearance & Granular, uniform and plump & - \\
\hline
\end{tabular}

Table 3. Properties of high viscosity modified asphalt.

\begin{tabular}{ccc}
\hline Index & Value & Specification Limits \\
\hline Penetration $25^{\circ} \mathrm{C}, 100 \mathrm{~g}, 5 \mathrm{~s}(0.1 \mathrm{~mm})$ & 44 & $40-60$ \\
Softening point $\left({ }^{\circ} \mathrm{C}\right)$ & 98.0 & $\geq 90$ \\
Ductility, $5^{\circ} \mathrm{C}, 5 \mathrm{~cm} / \mathrm{min}(\mathrm{cm})$ & 35 & $\geq 30$ \\
Dynamic viscosity, $60^{\circ} \mathrm{C}(\mathrm{Pa} \cdot \mathrm{s})$ & 440,806 & $\geq 400,000$ \\
Density, $25^{\circ} \mathrm{C}$ & 1.027 & - \\
After aging in rolling thin film oven & & \pm 0.6 \\
Mass change $(\%)$ & -0.023 & $\geq 65$ \\
Retained penetration, $25^{\circ} \mathrm{C}(\%)$ & 82.4 & $\geq 20$ \\
Retained ductility, $5{ }^{\circ} \mathrm{C}(\mathrm{cm})$ & 25 & \\
\hline
\end{tabular}

\subsection{Mix and Structure Design}

Asphalt concrete (AC) is widely used in the traditional pavement. Different from the traditional pavement, the concrete used in the permeable pavement is often called porous asphalt concrete (PAC). Besides, the maximum particle size of upper-surface is usually $13 \mathrm{~mm}$ in China, and for the mid-surface, it is usually $20 \mathrm{~mm}$. In addition, for better simulation effect, the test specimens were all made up of two layers. Traditional pavement specimen was made up of $4 \mathrm{~cm}$ thick AC13 mixture and $6 \mathrm{~cm}$ thick AC20 mixture. The permeable pavement specimens were made up of $4 \mathrm{~cm}$ thick PAC13 mixture and $6 \mathrm{~cm}$ thick AC20 mixture. Additionally, the different clogging situations were simulated by porosities ranged from $15 \%$ to $24 \%$.

\subsubsection{Mix Design}

The present study shows that the porosity of PAC13 is greatly influenced by the aggregate passing proportion of $4.75 \mathrm{~mm}\left(\mathrm{P}_{4.75}\right)$ and $2.36 \mathrm{~mm}\left(\mathrm{P}_{2.36}\right)$ [20]. So the porosity of PAC13 mixture was mainly adjusted by controlling $\mathrm{P}_{4.75}$ and $\mathrm{P}_{2.36}$. The gradation is shown in Table 4 and the gradation curves are shown in Figure 2. 
Table 4. Gradation of aggregate blends for asphalt mixture PAC13.

\begin{tabular}{|c|c|c|c|c|c|c|c|c|c|c|c|c|}
\hline \multicolumn{2}{|c|}{ Sieve Size } & 16 & 13.2 & 9.5 & 4.75 & 2.36 & 1.18 & 0.6 & 0.3 & 0.15 & 0.075 & Porosity \\
\hline \multicolumn{2}{|c|}{ Upper limit } & 100 & 100 & 71 & 30 & 22 & 18 & 14.0 & 12 & 9 & 7 & \\
\hline \multicolumn{2}{|c|}{ Lower limit } & 100 & 90 & 40 & 10 & 8 & 6 & 4 & 3 & 3 & 3 & \\
\hline \multirow{5}{*}{ Gradation } & 1 & 100 & 92.7 & 56.8 & 16.7 & 10.4 & 7.9 & 6.6 & 5.2 & 4.5 & 3.8 & $20.79 \%$ \\
\hline & 2 & 100 & 95.0 & 65.0 & 25.0 & 16 & 14.0 & 11.0 & 9.0 & 6.0 & 4.0 & $19.66 \%$ \\
\hline & 3 & 100 & 95.0 & 67.5 & 26.5 & 18.5 & 14.3 & 10.0 & 8.0 & 6.0 & 4.0 & $18.11 \%$ \\
\hline & 4 & 100 & 95.0 & 70.0 & 28.0 & 21 & 14.5 & 10.5 & 9.0 & 6.0 & 4.0 & $16.36 \%$ \\
\hline & 5 & 100 & 95.0 & 45.0 & 10.0 & 8.0 & 7.0 & 6.0 & 5.0 & 4.0 & 3.0 & $23.05 \%$ \\
\hline
\end{tabular}

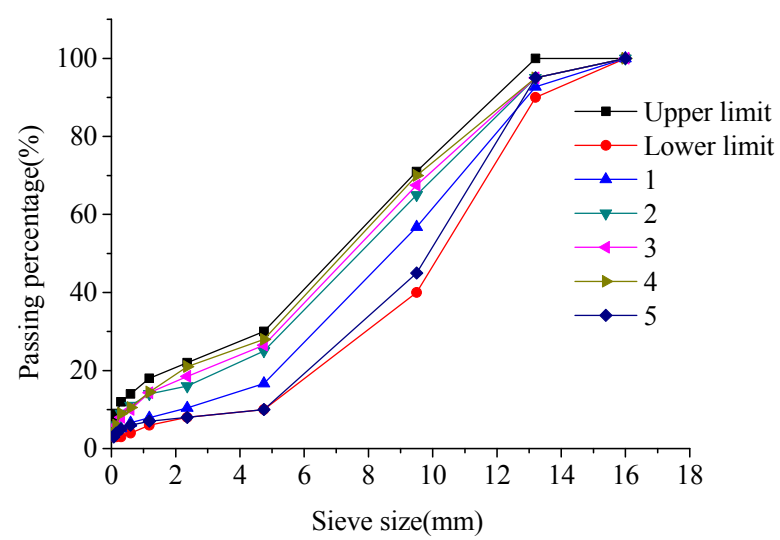

Figure 2. Gradation of PAC13 asphalt mixture.

In addition, the gradations of aggregate blends for asphalt mixture $\mathrm{AC} 13$ and $\mathrm{AC} 20$ are listed in Tables 5 and 6.

Table 5. Gradation AC13 asphalt mixture.

\begin{tabular}{ccccccccccc}
\hline Sieve Size & $\mathbf{1 6}$ & $\mathbf{1 3 . 2}$ & $\mathbf{9 . 5}$ & $\mathbf{4 . 7 5}$ & $\mathbf{2 . 3 6}$ & $\mathbf{1 . 1 8}$ & $\mathbf{0 . 6}$ & $\mathbf{0 . 3}$ & $\mathbf{0 . 1 5}$ & $\mathbf{0 . 0 7 5}$ \\
\hline Upper limit & 100 & 100 & 85 & 68 & 50 & 38 & 28 & 20 & 15 & 8 \\
Lower limit & 100 & 90 & 68 & 38 & 24 & 15 & 10 & 7 & 5 & 4 \\
Gradation & 100 & 96.9 & 70.2 & 41.8 & 29.1 & 19.9 & 14.4 & 10.5 & 8.2 & 5 \\
\hline
\end{tabular}

Table 6. Gradation AC20 asphalt mixture.

\begin{tabular}{ccccccccccccc}
\hline Sieve Size & $\mathbf{2 6 . 5}$ & $\mathbf{1 9 . 0}$ & $\mathbf{1 6 . 0}$ & $\mathbf{1 3 . 2}$ & $\mathbf{9 . 5}$ & $\mathbf{4 . 7 5}$ & $\mathbf{2 . 3 6}$ & $\mathbf{1 . 1 8}$ & $\mathbf{0 . 6}$ & $\mathbf{0 . 3}$ & $\mathbf{0 . 1 5}$ & $\mathbf{0 . 0 7 5}$ \\
\hline Upper limit & 100 & 100 & 95 & 86 & 70 & 48 & 33 & 23 & 16 & 11 & 9 & 6 \\
Lower limit & 100 & 90 & 83 & 73 & 56 & 35 & 22 & 15 & 10 & 6 & 5 & 4 \\
Gradation & 100 & 96.8 & 89.4 & 78.9 & 60.9 & 42.8 & 29.3 & 21.1 & 14.6 & 10.7 & 8.3 & 5.5 \\
\hline
\end{tabular}

\subsubsection{Structure Design}

A total of 6 experimental groups were set up in the test. The size of the specimens was $30 \mathrm{~cm} \times 30 \mathrm{~cm} \times 10 \mathrm{~cm}$. They were divided into 2 types: traditional group (AC) and permeable group (S1-S5). The specific combination form is shown in Table 7. Additionally, in order to facilitate later experiment, every gradation of asphalt mixture was also made into rutting plate specimens in the size of $30 \mathrm{~cm} \times 30 \mathrm{~cm} \times 5 \mathrm{~cm}$ (Labeling AC13, AC20 and PAC13-1-PAC13-5). 
Table 7. Structure design of specimens.

\begin{tabular}{cccc}
\hline Type & Porosity/Material (Upper Layer) & Porosity/Material (Lower Layer) & Label \\
\hline Traditional & AC13 & AC20 & AC \\
\hline & $16.68 \% /$ PAC13 & AC20 & S1 \\
Permeable & $18.11 \% /$ PAC13 & AC20 & S2 \\
& $19.66 \% /$ PAC13 & AC20 & S3 \\
& $20.79 \% /$ PAC13 & AC20 & S4 \\
& $23.05 \% /$ PAC13 & AC20 & S5 \\
\hline
\end{tabular}

\subsubsection{Specimen Preparation}

The temperature field in the pavement needed to be monitored in the later tests. Thus, the thermocouple sensors should be embedded in the specimen preparation process. The length of the thermocouples inside the specimen was $15 \mathrm{~cm}$, and the depth of $2 \mathrm{~cm}, 4 \mathrm{~cm}, 7 \mathrm{~cm}$ and $10 \mathrm{~cm}$ respectively, which was shown in Figure 3. Two thermocouples were embedded in each depth, and the temperature of each layer is expressed as the average value of the measured values of the two sensors. In order to facilitate the embedment of the sensor, the customized model in Figure 4a was made. The specimens were prepared by the method of layered compaction. After the lower layer was cooled, the upper layer was added and compacted.

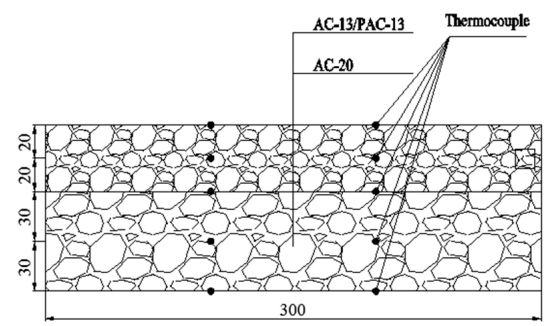

Figure 3. Location of thermocouple embedded.

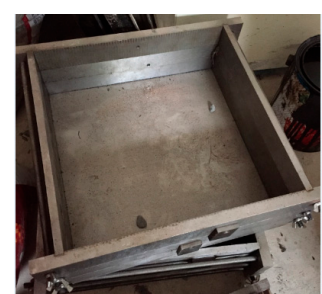

(a)

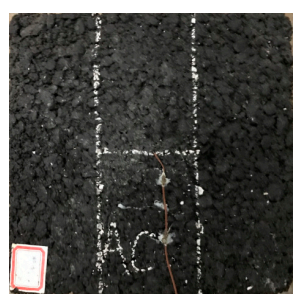

(b)

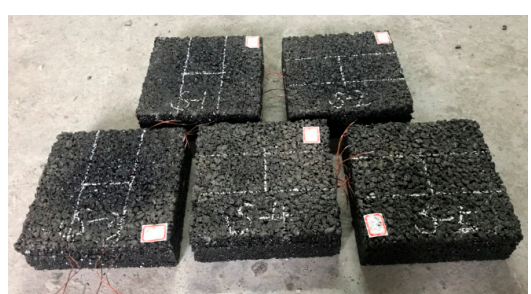

(c)

Figure 4. (a) Customized models; (b) AC specimen; (c) S1-S5 specimens.

\subsection{Determination of Thermal Properties}

Parameters in the heat conduction model included mass density, specific heat and thermal conductivity of the mixture. The mass density of the mixture was expressed by the bulk density. In addition, in the study of the thermally physical properties of asphalt mixtures, Zou [21] proposed that the specific heat can be expressed in a parallel model, which is shown as follows:

$$
A_{c}=\sum A_{i} B_{i}
$$

where $A_{c}$ is the specific heat of asphalt mixtures; $A_{i}$ is the specific heat of the $i$-th component; $B_{i}$ is mass fraction of the $i$-th component.

The mass densities and specific heat of each gradation are shown in Table 8. 
Table 8. Specific heat and density of $5 \mathrm{~cm}$ thick specimens.

\begin{tabular}{cccc}
\hline Numbering & Porosity $(\%)$ & Specific Heat $(\mathbf{J} / \mathbf{( k g} \cdot \mathbf{K}))$ & Density $\left(\mathbf{k g} / \mathbf{m}^{3}\right)$ \\
\hline PAC13-1 & 16.68 & 926.88 & 2229.52 \\
PAC13-2 & 18.11 & 926.09 & 2194.62 \\
PAC13-3 & 19.66 & 926.09 & 2142.77 \\
PAC13-4 & 20.79 & 925.30 & 2116.84 \\
PAC13-5 & 23.05 & 915.82 & 2090.92 \\
AC13 & - & 922.51 & 2420.96 \\
AC20 & - & 920.60 & 2381.07 \\
\hline
\end{tabular}

The thermal conductivity of the mixture was related to the conductivity of aggregate, asphalt, mineral powder and porosity. Williamson [22] once put forward a formula:

$$
k_{m}=\left(k_{a}\right)^{g} \cdot\left(k_{b}\right)^{h} \cdot\left(k_{v}\right)^{i} \cdot\left(k_{w}\right)^{j}
$$

where $k_{a}, k_{b}, k_{v}$ and $k_{w}$ are the thermal conductivity of the aggregate, asphalt, mineral powder and air respectively. G, h, $i$ and $j$ are volume fraction of each component. The thermal conductivities [23] of the components were listed in Table 9.

Table 9. Thermal conductivities of the components.

\begin{tabular}{ccccc}
\hline Index & Aggregate & Asphalt & Mineral Powder & Air \\
\hline Thermal conductivity $(\mathrm{W} /(\mathrm{m} \cdot \mathrm{K}))$ & 2.18 & 0.66 & 0.2 & 0.026 \\
\hline
\end{tabular}

In addition, the thermal conductivities of the specimens were also tested by heat flow meter method, the results of the test and Williamson's formula were shown in Table 10.

Table 10. Thermal conductivities of $5 \mathrm{~cm}$ thick specimens.

\begin{tabular}{cccc}
\hline \multirow{2}{*}{ Numbering } & \multirow{2}{*}{ Porosity (\%) } & \multicolumn{2}{c}{ Thermal Conductivity $(\mathbf{W} /(\mathbf{m} \cdot \mathbf{K}))$} \\
\cline { 3 - 4 } & & Williamson's Formula & Test \\
\hline PAC13-1 & 16.68 & 0.82 & 1.03 \\
PAC13-2 & 18.11 & 0.78 & 0.97 \\
PAC13-3 & 19.66 & 0.73 & 0.93 \\
PAC13-4 & 20.79 & 0.70 & 0.88 \\
PAC13-5 & 23.05 & 0.67 & 0.8 \\
AC13 & - & 1.07 & 1.15 \\
AC20 & - & 1.16 & 1.38 \\
\hline
\end{tabular}

From Table 10, for PAC13 mixtures, the calculation results of Williamson formula and the measured results decreased with the increase of porosity. The increasing trend is consistent, so it was considered whether there was linear relationship between them. To facilitate the analysis and comparison, the data of Table 10 is shown in Figure 5, and the relationship between the tested and calculated values was obtained by linear fitting.

Can be seen from Figure 5, it can be linear fitted well between test value and the theoretical value of the thermal conductivity of PAC mixture. So in this paper, a new model was proposed based on the Williamson formula to explain the relationship between thermal conductivity of the mixture and that of the components, which is shown as Equation (43):

$$
k=-0.365+1.808\left(k_{a}\right)^{g} \cdot\left(k_{b}\right)^{h} \cdot\left(k_{v}\right)^{i} \cdot\left(k_{w}\right)^{j}
$$




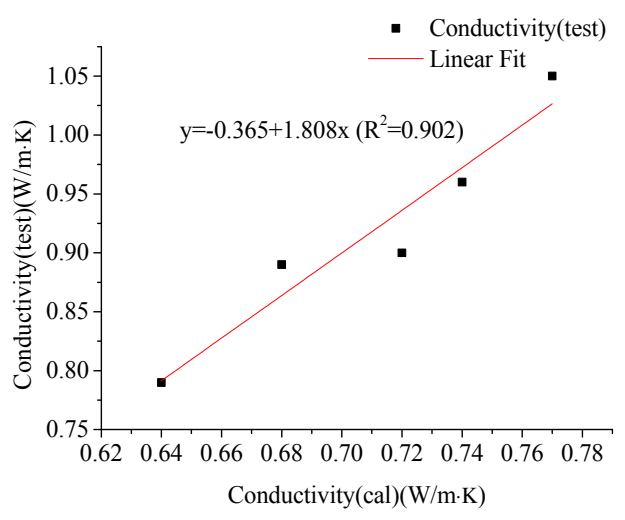

Figure 5. Thermal conductivities of $5 \mathrm{~cm}$ thick specimens.

\subsection{Test Method}

The infrared lamp was used to simulate the solar radiation in summer. Considering the size ratio of the vertical and horizontal directions of the road surface, the sides and the bottom of the rutting plate specimens can be set as an adiabatic surface while the upper surface was set as a mixed surface to exchange heat with the outside.

As the temperature of the road surface in summer was about $65-70{ }^{\circ} \mathrm{C}$, the target of the equilibrium temperature of the heating test was set in the gap. The AC specimen was used to adjust the height of the infrared light. When the specimen temperature reaches the equilibrium range, the height of the infrared lamp would be fixed. The result showed that when the height of the infrared lamp was controlled at $28 \mathrm{~cm}$ above the surface and the test lasting time was $60 \mathrm{~min}$, the temperature of the specimen surface would reach the target range and kept stable.

The heating tests were conducted after the height was determined. The infrared lamp should be cooled after each heating test to avoid the influence of the remaining warmth on the later test. The experimental devices were shown in Figure 6a. Additionally, in order to prevent the influence of wind, the enclosure was installed around the specimen, shown in Figure 6b.

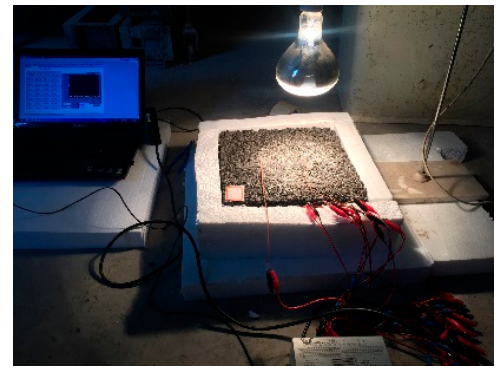

(a)

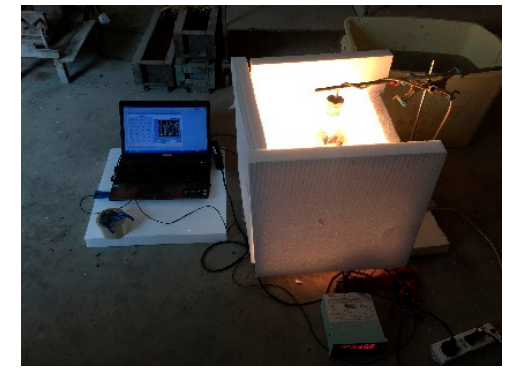

(b)

Figure 6. (a) The experimental devices; (b) The enclosure around the specimen.

\subsection{Data Comparison}

Several hypotheses were adopted in the theoretical calculation.

(1) The heating power on the infrared light remained constant during the test;

(2) The sides and the bottom of the specimen were adiabatic boundaries, and the upper surface of the specimen is a mixed boundary of fluid and solid;

(3) Each layer of asphalt mixture was isotropic materials;

(4) The thermal properties of asphalt mixture remained constant during the test;

(5) There was no thermal resistance between two linked layers. 
The AC specimen was set as the matched group. With the thermally physical properties of the AC specimen plugged into Equation (40) and surface temperature curve as the reference, the power of the infrared radiation was determined to be $0.157 \mathrm{~W} / \mathrm{mm}^{2}$. Then the thermal properties of the remaining specimens were also plugged into Equation (40). The results of theoretical calculation and tests are shown in the following figures.

Firstly, it can be found that the theoretical calculation results are similar with the actual results. So it can be determined that the model was suitable with the heat transfer of porous asphalt mixture, and it can be used to predict the temperature of the whole pavement.

In addition, it can be seen from Figures 7 and 8 that the temperature on the surface of the specimen rose fastest. As the test went on, the temperature rising curve of the specimen gradually became gentle and tended to be stable. In addition, by comparing the temperature among different depths, it can be concluded that the temperature conduction in the asphalt pavement had the hysteresis in the vertical direction. With the increase in depth, the hysteresis phenomenon became more obvious. Taking AC specimen as an example, the surface temperature changes rapidly in the first $5 \mathrm{~min}$. But at the bottom, the temperature had almost no change in $30 \mathrm{~min}$.

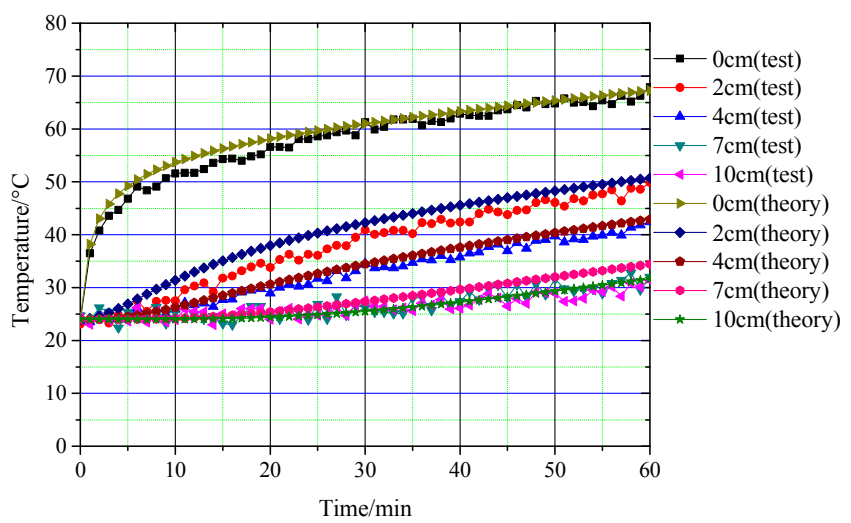

Figure 7. Results of theoretical calculation and tests of AC.

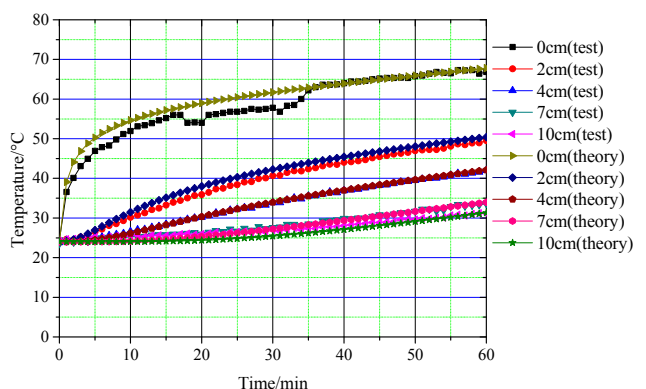

(a)

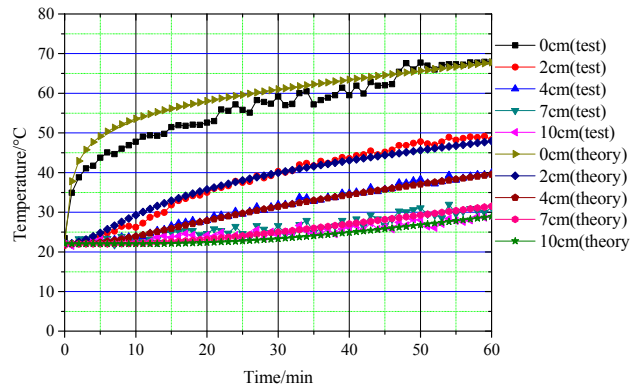

(c)

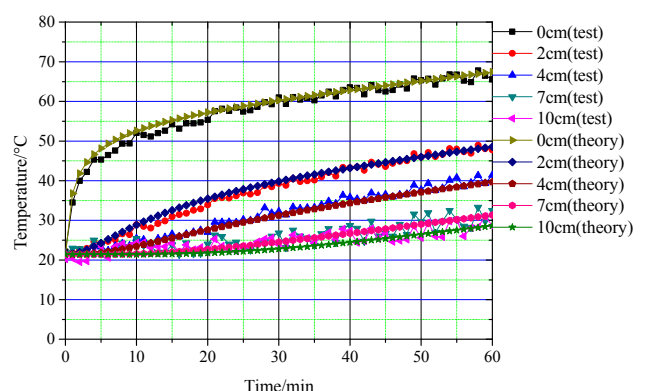

(b)

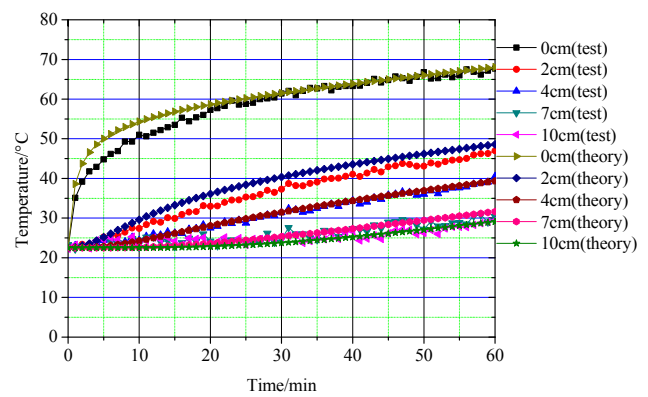

(d)

Figure 8. Cont. 


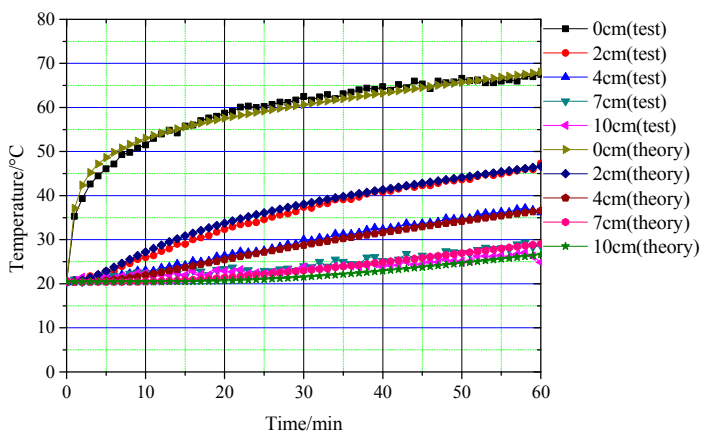

(e)

Figure 8. (a) Results of theoretical calculation and tests of $S 1 ;$ (b) Results of theoretical calculation and tests of S2; (c) Results of theoretical calculation and tests of S3; (d) Results of theoretical calculation and tests of S4; (e) Results of theoretical calculation and tests of S5.

The temperature of each depth of the specimens can also be obtained by the curves shown in the figures above. The temperature in the depth of $4 \mathrm{~cm}$ and $10 \mathrm{~cm}$ of each specimen was extracted and is listed in Table 11.

Table 11. Temperature in the specimens.

\begin{tabular}{ccccc}
\hline Specimen & Porosity/Material (Upper) & Porosity/Material (Lower) & Temperature in $\mathbf{4} \mathbf{~ c m ~}\left({ }^{\circ} \mathrm{C}\right)$ & Temperature in $\mathbf{1 0} \mathbf{~ c m ~}\left({ }^{\circ} \mathbf{C}\right)$ \\
\hline AC & AC13 & AC20 & 42.4 & 31.4 \\
S1 & $16.68 \% /$ PAC13 & AC20 & 42.0 & 31.2 \\
S2 & $18.11 \% /$ PAC13 & AC20 & 41.4 & 30.3 \\
S3 & $19.66 \% /$ PAC13 & AC20 & 40.8 & 29.5 \\
S4 & $20.79 \% /$ PAC13 & AC20 & 40.5 & 29.4 \\
S5 & $23.05 \% /$ PAC13 & AC20 & 40.0 & 28.9 \\
\hline
\end{tabular}

It can be visually seen from Table 11 that in both depth of $4 \mathrm{~cm}$ and $10 \mathrm{~cm}$, the temperatures in permeable pavements were lower than the traditional pavement. It showed that the cooling effect still existed in the permeable pavement under the extreme conditions of no wind on the surface or water in the void. Through the comparison of single layered PAC asphalt specimens, it can be found that with the increase of porosity, both of the temperature values in the two depths were showing a downward trend. The results showed that the cooling effect of drainage asphalt increased with the increase of void fraction. As the porosity of PAC13 layer changed from $16.68 \%$ to $23.05 \%$, the maximum temperature of permeable asphalt pavement at the depth of $4 \mathrm{~cm}$ and $10 \mathrm{~cm}$ were $0.4-2.4^{\circ} \mathrm{C}$ and $0.2-2.5^{\circ} \mathrm{C}$ lower than the traditional pavement respectively.

\section{The Cooling Performance of the Temperature Field with Different Porosities}

The pavement was usually divided into six layers. The upper surface was AC13/PAC13, the middle surface was AC20, and the lower surface was AC25. The order and thickness of each layer was shown in Figure 9, where CTB stands for cement treated base, LS stands for lime-stabilized soil and SG stands for subgrade.

\begin{tabular}{rl}
$\mathrm{AC} 13 / \mathrm{PAC} 13$ & $4 \mathrm{~cm}$ \\
\hline $\mathrm{AC} 20$ & $6 \mathrm{~cm}$ \\
\hline $\mathrm{AC} 25$ & $8 \mathrm{~cm}$ \\
\hline $\mathrm{CTB}$ & $20 \mathrm{~cm}$ \\
\hline $\mathrm{LS}$ & $10 \mathrm{~cm}$ \\
\hline $\mathrm{SG}$ & $300 \mathrm{~cm}$ \\
\hline
\end{tabular}

Figure 9. Structure of the pavement. CTB: cement treated base; LS: lime-stabilized soil; SG: subgrade. 
The thermally physical properties of each layer were shown in Table 12.

Table 12. Thermally physical properties of each layer.

\begin{tabular}{|c|c|c|c|}
\hline Layer & Density $\left(\mathrm{kg} / \mathrm{m}^{3}\right)$ & Specific Heat $\left(\mathrm{J} \cdot \mathrm{kg}^{-1} \cdot \mathrm{K}^{-1}\right)$ & Conductivity $\left(\mathrm{J} \cdot \mathrm{m}^{-1} \cdot \mathrm{h}^{-1} \cdot \mathrm{K}^{-1}\right)$ \\
\hline $\mathrm{AC} 25$ & 2300 & 924.9 & 1.3 \\
\hline СТВ & 2200 & 911.7 & 1.56 \\
\hline LS & 2100 & 942.9 & 1.43 \\
\hline SG & 1800 & 1040 & 1.56 \\
\hline
\end{tabular}

After the structural form was determined, it was necessary to ascertain the thermal physical parameters of each layer, the solar radiation intensity and the variation law of the daily air temperature. The amount of solar radiation [12] in the model was expressed as the form of $q(t)$ by Equation (44).

$$
q(t)=\left\{\begin{array}{cc}
0 & 0 \leq t \leq 12-\frac{c}{2} \\
q_{0} \cos m \omega(t-12) & 12+\frac{c}{2} \leq t \leq 12+\frac{c}{2} \\
0 & 12+\frac{c}{2} \leq t \leq 24
\end{array}\right.
$$

where $q_{0}$ is the maximum radiation intensity at midday, $q_{0}=0.131 \mathrm{mQ}, m=12 / \mathrm{c} ; \mathrm{Q}$ is the total amount of solar radiation in the day, $\mathrm{J} / \mathrm{m}^{2} ; c$ is the actual effective sunshine time, $h$; and $\omega$ is angular frequency, $\omega=2 \pi / 24$, rad.

The changing rule of the daily air temperature [12] was shown in Equation (27)

$$
T_{a}=\bar{T}_{a}+T_{m}\left[0.96 \sin \omega\left(t-t_{0}\right)+0.14 \sin 2 \omega\left(t-t_{0}\right)\right]
$$

where $T_{a}$ is the air temperature, ${ }^{\circ} \mathrm{C} ; \bar{T}_{a}$ is the average value of the temperature in a day, $\bar{T}_{a}=\left(T_{\max }+T_{\min }\right) / 2,{ }^{\circ} \mathrm{C} ; T_{m}$ is the daily temperature variation, $T_{m}=\left(T_{\max }-T_{\min }\right) / 2,{ }^{\circ} \mathrm{C} ; t_{0}$ is the initial phase; and $T_{\max }=40^{\circ} \mathrm{C}, T_{\min }=26^{\circ} \mathrm{C}, t_{0}=3$.

Because the temperature at the bottom of the middle surface has the greatest influence on rutting, the change of temperature in the depth of $10 \mathrm{~cm}$ within $24 \mathrm{~h}$ was studied. The calculation results of AC and S5 were shown in Figure 10.

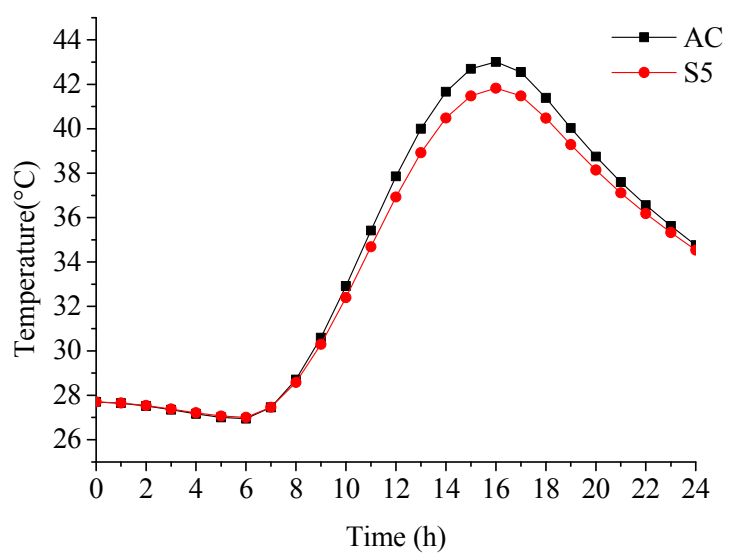

Figure 10. Temperature at the bottom of the middle surface.

It can be seen from Figure 10 that the temperature would be more stable and the maximum temperature would lower in the permeable pavement. It indicated that the permeable pavement could reduce the internal maximum temperature and be more environmental-friendly. The maximum temperatures at the bottom of middle surface of each pavement type were calculated and shown in 
Table 13. Additionally, the cooling performance was represented by the reduced temperature between $\mathrm{AC}$ and permeable pavements.

Table 13. Cooling performance of all structures.

\begin{tabular}{ccc}
\hline Type & Maximum Temperature $\left({ }^{\circ} \mathbf{C}\right)$ & Reduced Temperature $\left({ }^{\circ} \mathbf{C}\right)$ \\
\hline AC & 43.00 & 0.00 \\
S1 & 42.71 & 0.29 \\
S2 & 42.51 & 0.49 \\
S3 & 42.37 & 0.63 \\
S4 & 42.18 & 0.82 \\
S5 & 41.82 & 1.18 \\
\hline
\end{tabular}

From the theoretical calculation results, it can be seen that the cooling performance would be better with the increase of porosity. The maximum value of cooling performance could reach $1.18^{\circ} \mathrm{C}$. So it was an effective method to contrast the urban heat island effect by adopting permeable pavement in the building of sponge cities. The results in Table 13 were shown in Figure 11.

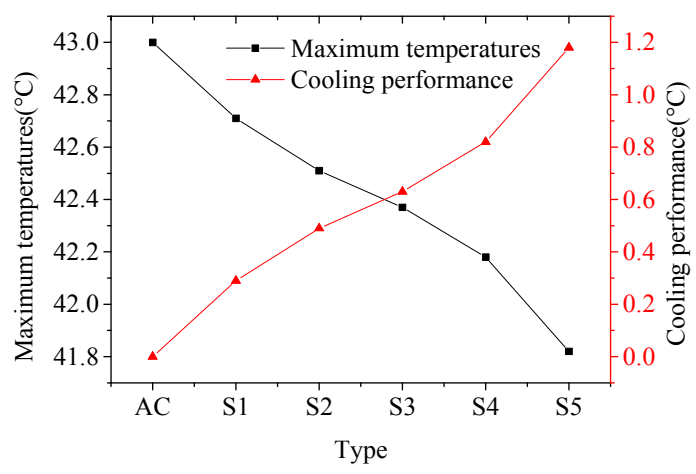

Figure 11. Cooling performance of the structures.

In addition, for the permeable pavement, as the porosity was $16.68 \%$, the maximum temperature of the bottom of the middle surface was only $0.29{ }^{\circ} \mathrm{C}$ lower than that of traditional pavement. There was almost no cooling performance, and the porosity of permeable pavement was usually $20 \%$, whose cooling performance was about $0.63{ }^{\circ} \mathrm{C}$. So it can be judged that the cooling performance of the permeable pavement would reduce by over $50 \%$ as the porosity changed from $20 \%$ to $16.68 \%$. Additionally, there was a linear relationship between the cooling performance and porosity in the single layered permeable pavements, which was shown in Figure 12.

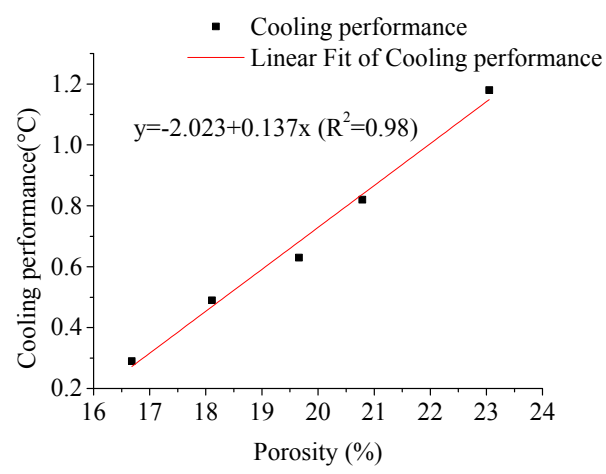

Figure 12. Relationship between the cooling performance and porosity. 
The simplified model of cooling performance and porosity can be used to judge the attenuation of cooling effect of permeable asphalt pavement quickly in practical engineering and determine the clean cycle of the pavement.

\section{Conclusions}

In this paper, the temperature field distribution model of a layered pavement system was obtained based on Green's function. The internal temperature of PAC specimens with different porosities was studied by comparing theory calculations to test results. The temperature field model was applied to evaluate cooling performance of the permeable pavement under different clogging conditions. Through the analysis of the results, the following conclusions were obtained:

(1) The prediction model of the temperature field of permeable pavement was obtained based on Green's function, and the model was verified by the experimental results. The values of theoretical calculation were close to the experimental results. This indicated that the model had a wide applicability, which could be applied to the theoretical analysis of heat conduction problem for asphalt pavement.

(2) The linear fitted model was proposed based on the Williamson formula and the results of the test. The model could explain the relationship between thermal conductivity of the mixture and that of the components well.

(3) According to the results of test, the cooling performance of pavement became worse with the attenuation of porosity. When the porosity of permeable asphalt pavement reaches $23.05 \%$, the cooling performance at the depth of $10 \mathrm{~cm}$ could reach $1.18^{\circ} \mathrm{C}$. When the porosity reached $16.68 \%$, the cooling effect declined to $0.29^{\circ} \mathrm{C}$.

(4) Void clogging has a great influence on the cooling effect of drainage pavement. At present, the porosity of single layered drainage pavement is about $20 \%$. The cooling effect of the pavement under this porosity was about $0.63{ }^{\circ} \mathrm{C}$. If the porosity declined by about three percent, the cooling performance would be less than half of the original.

(5) Through the regression analysis of the relationship between cooling performance and porosity in the permeable pavement, a linear model was set up. The model could be used as a reference for rapid judgment of pavement cooling performance in the field, so as to determine the cleaning cycle of permeable pavement.

Acknowledgments: The authors would like to acknowledge Technological Innovation Project of Ministry of Transport of the People's Republic of China (2015315Q11020), Jiangsu Scientific and Technological Development Program (BE2015349), National Key Technology Research and Development Program of the Ministry of Science and Technology of China (2015BAL02B00) and the Fundamental Research Funds for the Central Universities (NQ2018001) for its financial support in this project.

Author Contributions: In this article, Jianguang Xie conceived and designed the experiments; Sicheng Jia performed the experiments; Lei Gao, Sicheng Jia and Hua Li analyzed the data; Jianguang Xie contributed analysis tools; Sicheng Jia wrote the paper.

Conflicts of Interest: The authors declare no conflict of interest.

\section{References}

1. Buyung, N.R.; Ghani, A.N.A. Permeable pavements and its contribution to cooling effect of surrounding temperature. In Proceedings of the International Conference of Global Network for Innovative Technology and Awam International Conference in Civil Engineering, Bukit Jambul, Malaysia, 8-9 August 2017; p. 170003.

2. Van Thanh, D.; Feng, C.P. Study on Marshall and Rutting test of SMA at abnormally high temperature. Constr. Build. Mater. 2013, 47, 1337-1341. [CrossRef]

3. Walubita, L.F.; Faruk, A.N.M.; Zhang, J.; Hu, X.; Lee, S.I. The Hamburg rutting test-Effects of HMA sample sitting time and test temperature variation. Constr. Build. Mater. 2016, 108, 22-28. [CrossRef] 
4. Javilla, B.; Mo, L.; Hao, F.; Shu, B.; Wu, S. Multi-stress loading effect on rutting performance of asphalt mixtures based on wheel tracking testing. Constr. Build. Mater. 2017, 148, 1-9. [CrossRef]

5. Zheng, Y.; Zhang, P.; Liu, H. Correlation between pavement temperature and deflection basin form factors of asphalt pavement. Int. J. Pavement Eng. 2017, 1-10. [CrossRef]

6. Al-Rubaei, A.M.; Stenglein, A.L.; Viklander, M.; Blecken, G.T. Long-Term Hydraulic Performance of Porous Asphalt Pavements in Northern Sweden. J. Irrig. Drain. Eng. 2013, 139, 499-505. [CrossRef]

7. Coleri, E.; Kayhanian, M.; Harvey, J.T.; Yang, K.; Boone, J.M. Clogging evaluation of open graded friction course pavements tested under rainfall and heavy vehicle simulators. J. Environ. Manag. 2013, 129, 164-172. [CrossRef] [PubMed]

8. Cantisani, G.; D’Andrea, A.; Di Mascio, P.; Loprencipe, G. Reliance of Pavement Texture Characteristics on Mix-Design and Compaction Process. In 8th RILEM International Symposium on Testing and Characterization of Sustainable and Innovative Bituminous Materials; Springer: Dordrecht, The Netherlands, 2016; pp. 271-281.

9. Hermansson, A. Simulation model for calculating pavement temperature including maximum temperature. Transp. Res. Rec. 2000, 1699, 134-141. [CrossRef]

10. Hermansson, A. A mathematical model for calculating pavement temperatures, comparisons between calculated and measured temperatures. Transp. Res. Rec. J. Transp. Res. Board 2001, 1746, 180-188. [CrossRef]

11. Barber, E.S. Calculation of maximum pavement temperatures from weather reports. Highw. Res. Board Bull. $1957,168,1-8$.

12. Straub, A.; Schenck, H.N., Jr.; Przbycien, F.E. Bituminous Pavement Temperature Related to Climate. Highw. Res. Rec. 1968, 256, 53-77.

13. Yan, Z. Analysis of the Temperature Field in Layerd Pavement System. J. Tongji Univ. 1984, 3, 76-85. (In Chinese)

14. Liu, C.; Yuan, D. Temperature distribution in layered road structures. J. Transp. Eng. 2000, 126, 93-95. [CrossRef]

15. Gao, L.; Ni, F.; Charmot, S. High-temperature performance of multilayer pavement with cold in-place recycling mixtures. Road Mater. Pavement Des. 2014, 15, 804-819. [CrossRef]

16. Wang, D. Analytical approach to predict temperature profile in a multilayered pavement system based on measured surface temperature data. J. Transp. Eng. 2012, 138, 674-679. [CrossRef]

17. Chen, J.; Li, L.; Zhao, L.; Dan, H.-C.; Yao, H. Solution of pavement temperature field in "Environment-Surface" system through Green's function. J. Central South Univ. 2014, 21, 2108-2116. [CrossRef]

18. Chen, J.; Wang, H.; Zhu, H. Analytical approach for evaluating temperature field of thermal modified asphalt pavement and urban heat island effect. Appl. Therm. Eng. 2017, 113, 739-748. [CrossRef]

19. Sreedhar, S.; Biligiri, K.P. Development of pavement temperature predictive models using thermophysical properties to assess urban climates in the built environment. Sustain. Cities Soc. 2016, 22, 78-85. [CrossRef]

20. Xing, M. Research on Composition Design and Performance of Pervious Asphalt Mixture. Master's Thesis, Chang'an University, Xi'an, China, 2007. (In Chinese)

21. Zou, L. Research on Thermal Physical Parameters of Asphalt Mixture. Master's Thesis, Chang'an University, Xi'an China, 2011. (In Chinese)

22. Williamson, R.H. Effects of environment on pavement temperature. Intl. Conf Structural Design Proc. 1972, 9, 144-158.

23. Li, X. Research on Thermophysical Characteristic of Asphalt Mixture. Master's Thesis, Harbin Institute of Technology, Harbin, China, 2007. (In Chinese)

(C) 2018 by the authors. Licensee MDPI, Basel, Switzerland. This article is an open access article distributed under the terms and conditions of the Creative Commons Attribution (CC BY) license (http://creativecommons.org/licenses/by/4.0/). 